\title{
Contribution of multiple reflections to light utilization efficiency of submicron hollow $\mathrm{TiO}_{2}$ photocatalyst
}

\author{
Hongyan $\mathrm{Liu}^{1,2,3^{*}}$, Hua $\mathrm{Ma}^{2}$, Jibong $\mathrm{Joo}^{2,4}$ and Yadong $\mathrm{Yin}^{2 *}$
}

\begin{abstract}
In this work, we carried out both theoretical calculation and experimental studies to reveal the contribution of hollow geometry to the light utilization efficiency of the $\mathrm{TiO}_{2}$ photocatalysts in diluted aqueous solution. It is found that the single or multi-shelled hollow structures do not induce significant multiple reflections within the shells as widely believed in previous reports, and therefore the geometric factor has minimal contribution to the improvement of the light utilization efficiency of the photocatalyst. To design $\mathrm{TiO}_{2}$ photocatalysts with higher activity, it is more appropriate to focus on the improvement of the crystallinity, diffusion, surface area, and dispersity of the catalysts, rather than their geometric shapes.
\end{abstract}

Keywords: multiple reflections, photocatalysis, $\mathrm{TiO}_{2}$, hollow shell

\section{INTRODUCTION}

Hollow structures of inorganic materials have attracted much attention because of their widespread potential applications in catalysis, controlled delivery, photonic devices, biomedicine, and energy [1-7]. For applications in environmental and energy-related systems, various hollow spheres of metal, metal oxide, and carbon-based materials have been used in dye-sensitized solar cells [8], photocatalysis [9], fuel cells [10], lithium ion batteries [11], and supercapacitors [12]. It has been proven that the unique structure of hollow spheres provides an enhanced surface-to-volume ratio and reduced transport lengths for both mass and charge transport [13]. Particular interests have been attracted to the synthesis of hollow structures of $\mathrm{TiO}_{2}$, one of the most widely studied semiconducting oxide materials, and their applications in solar energy conversion
[14]. In addition to the intrinsic materials characteristics including low cost, low toxicity, and high chemical and optical stability $[15,16]$, hollow nanostructures of $\mathrm{TiO}_{2}$ are believed to be able to provide a high active surface area, reduced diffusion resistance, and improved accessibility, which are beneficial features for photocatalysis. We have previously synthesized mesoporous hollow $\mathrm{TiO}_{2}$ shells with high surface areas through a surface-protected calcination process, revealed how the surface coating of another oxide or polymer could affect the crystallinity and the catalytic activity of the shells, and demonstrated that the phase composition, degree of crystallinity, surface area, and dispersity of $\mathrm{TiO}_{2}$ were important features required for photocatalysis [17-20].

In solar energy conversion, one of the widely emphasized advantages of the $\mathrm{TiO}_{2}$ hollow structures is the enhanced light utilization efficiency. For example, Li et al. [21] found that the photocatalytic activity of the "semi-hollow" core-shell structured $\mathrm{TiO}_{2}$ increased compared to the "fully-hollow" structured $\mathrm{TiO}_{2}$, suggesting that the multiple reflections of the incident light within the interior cavity of the hollow structure resulted in an enhanced light harvesting efficiency. This claim of enhancement of the photocatalytic activity by multiple reflections was echoed by others for $\mathrm{TiO}_{2}$ hollow structures [22-25], and also claimed later for other hollow materials such as $\mathrm{ZnO}[26,27], \mathrm{NiO}$ [28], $\mathrm{SnO}$ [29], $\mathrm{CdS}$ [30], $\mathrm{Fe}_{2} \mathrm{O}_{3}$ [31] and carbon nitride [32]. However, as generally known, the multiple reflections within the interior cavity should occur only when the cavity diameter is much larger than the wavelength of the incident light $[33,34]$. Since many of the previous claims were

\footnotetext{
${ }^{1}$ Key Laboratory of Luminescent and Real-Time Analytical Chemistry, Ministry of Education, College of Chemistry and Chemical Engineering, Southwest University, Chongqing 400715, China

${ }^{2}$ Department of Chemistry and UCR Center for Catalysis, University of California, Riverside, CA 92521, USA

${ }^{3}$ College of Chemistry and Chemical Engineering, Lanzhou University, Lanzhou 730000, China

${ }^{4}$ Department of Chemical Engineering, Konkuk University, 120 Neungdong-Ro, Gwangjin-Gu, Seoul, Republic of Korea

*Corresponding authors (emails: liuhy860@swu.edu.cn (Liu H); yadong.yin@ucr.edu (Yin Y))
} 
made based on submicron hollow structures, it remained a question if hollow structures of this dimension can indeed induce multiple reflections and benefit the light utilization efficiency of the photocatalysts.

In this work, we carried out both theoretical calculation and experimental studies to reveal the contribution of hollow geometry to the light utilization efficiency of the $\mathrm{TiO}_{2}$ photocatalyst. We show that the hollow or multi-shelled hollow structures do not help much in improving the light utilization efficiency of the materials for photocatalysis. Calculations based on Mie scattering theory and experimental comparison of the photocatalytic activity of the $\mathrm{TiO}_{2}$ hollow shells with that of crushed ones reveal that multiple reflections of $365 \mathrm{~nm}$ UV light are not notable in submicron $\mathrm{TiO}_{2}$ hollow shells. The photocatalytic performance of $\mathrm{TiO}_{2}$ hollow structures may be enhanced by the Mie resonances when the diameters of the $\mathrm{TiO}_{2}$ shells match with the wavelength of the incident light. However, the activity enhancement is found to be still minor compared with other parameters such as crystallinity, diffusion resistance, surface area, and solution dispersibility of the catalyst.

\section{EXPERIMENTAL SECTION}

\section{Chemicals}

Tetraethylorthosilicate (TEOS, 99\%), poly(vinyl pyrrolidone) (PVP, $\left.\quad M_{\mathrm{w}} \sim 40,000\right), \quad$ ammonium hydroxide $\left(\mathrm{NH}_{3} \cdot \mathrm{H}_{2} \mathrm{O}, \quad 28 \%\right.$ by weight in water), were purchased from Sigma-Aldrich. Ethanol was obtained from Fisher. Tetrabutyl orthotitanate (TBOT, 99\%) was purchased from Fluka. Absolute ethyl alcohol (200 proof) was purchased from Gold Shield Chemical. All chemicals were used as received without further purification. Deionized water was used throughout the experiments.

\section{Synthesis}

$\mathrm{SiO}_{2} @ \mathrm{TiO}_{2}$

Colloidal silica templates were prepared through a modified Stöber method $[35,36]$. TEOS $(0.86 \mathrm{~mL})$ was mixed with deionized water $(4.3 \mathrm{~mL})$ and ethanol $(23 \mathrm{~mL})$ and an aqueous solution of ammonia (28\%), the size of $\mathrm{SiO}_{2}$ could be tuned by adjusting the concentration of ammonia. By adding $0.3,0.45,0.55,0.62$ and $1 \mathrm{~mL}$ of ammonia, the size of the $\mathrm{SiO}_{2}$ particles is $90,140,200,330$ and $490 \mathrm{~nm}$, respectively. After stirring for $4 \mathrm{~h}$, the $\mathrm{SiO}_{2}$ particles were separated by centrifugation, washed three times with ethanol, and then re-dispersed in $20 \mathrm{~mL}$ of ethanol. The above silica solution $(5 \mathrm{~mL})$ was dispersed in a mixture of ethanol (15
$\mathrm{mL})$ and acetonitrile $(7 \mathrm{~mL})$. After adding ammonia aqueous solution $(28 \%, 0.2 \mathrm{~mL})$, TBOT $(0.4 \mathrm{~mL})$ in a mixture of ethanol $(3 \mathrm{~mL})$ and acetonitrile $(1 \mathrm{~mL})$ was injected into the mixture. After stirring for $3 \mathrm{~h}$, the precipitate was isolated by centrifugation, washed with ethanol to give $\mathrm{SiO}_{2} @ \mathrm{TiO}_{2}$ core-shell composites.

\section{$\mathrm{SiO}_{2} @ \mathrm{TiO}_{2} @ S i \mathrm{O}_{2}$}

Above $\mathrm{SiO}_{2} @ \mathrm{TiO}_{2}$ particles were dispersed in $20 \mathrm{~mL}$ of water, treated with PVP $(0.2 \mathrm{~g})$ overnight to allow for the adsorption of PVP onto the $\mathrm{TiO}_{2}$ surface, separated from solution by centrifugation, and then re-dispersed in $23 \mathrm{~mL}$ ethanol. The solution of $\mathrm{SiO}_{2} @ \mathrm{TiO}_{2}$ was sequentially mixed with water $(4.3 \mathrm{~mL})$, TEOS $(0.8 \mathrm{~mL})$ and aqueous ammonia $(28 \%, 0.62 \mathrm{~mL})$. After stirring for $4 \mathrm{~h}$, the resulting $\mathrm{SiO}_{2} @ \mathrm{TiO}_{2} @ \mathrm{SiO}_{2}$ particles were centrifuged, washed three times with ethanol and dried under vacuum.

\section{Calcination and etching}

To crystallize the amorphous $\mathrm{TiO}_{2}$ shell, the samples were dried under vacuum and heated in air to $900^{\circ} \mathrm{C}$ at a rate of $2.5^{\circ} \mathrm{C} \mathrm{min}{ }^{-1}$ then held for $2 \mathrm{~h}$ and cooled to room temperature. To obtain hollow shells by removal of the $\mathrm{SiO}_{2}$ core and $\mathrm{SiO}_{2}$ shell, the calcined sample $(100 \mathrm{mg})$ was dispersed in an aqueous $\mathrm{NaOH}$ solution $\left(20 \mathrm{~mL}, 0.5 \mathrm{~mol} \mathrm{~L}^{-1}\right)$, which was then stirred for $4 \mathrm{~h}$ at $90^{\circ} \mathrm{C}$. The etched microspheres were centrifuged and washed several times with deionized water and ethanol and dried under vacuum to obtain the final hollow shells.

\section{Void@TiO $@$ @oid@TiO 2}

The above $\mathrm{SiO}_{2} @ \mathrm{TiO}_{2} @ \mathrm{SiO}_{2}$ with $330 \mathrm{~nm} \mathrm{SiO}_{2}$ as core template was coated with another layer of $\mathrm{TiO}_{2}$ and $\mathrm{SiO}_{2}$, followed by calcination and etching, resulting in the $\mathrm{TiO}_{2}$ double-shelled structure void@ $\mathrm{TiO}_{2} @$ void@ $\mathrm{TiO}_{2}$, noted as D-T550. To fabricate $\mathrm{TiO}_{2}$ double-shelled structure with larger inter-shell distance, the process of $\mathrm{SiO}_{2}$ coating on $\mathrm{SiO}_{2} @ \mathrm{TiO}_{2}$ was repeated, and then followed the same $\mathrm{TiO}_{2}$ coating procedure. The product was noted as D-T670.

\section{Characterization}

The sample morphology was characterized using transmission electron microscopy (TEM) (Tecnai12). Samples were prepared by placing a drop of a diluted alcohol dispersion of the products on the surface of a copper grid. Crystal phases were determined by X-ray diffraction (XRD) analysis using a Bruker D8 advance diffractometer with $\mathrm{Cu}-\mathrm{Ka}$ radiation $(\lambda=1.5406 \AA)$. Nitrogen adsorption isotherms were obtained at $77 \mathrm{~K}$ using a nitrogen sorption instrument (Quantachrome NOVA 4200e). Brunauer-Emmert-Teller 
(BET) calculations utilized the adsorption branch of the isotherm. The crushing treatments for silica hollow particles were carried out by grinding $20 \mathrm{mg}$ sample in an agate mortar by hand for about $5 \mathrm{~min}$.

\section{Catalytic activity tests}

The photocatalytic activity was evaluated by following the degradation of Rhodamine $\mathrm{B}(\mathrm{RhB})$ as a function of time. Before the photocatalytic test was initiated, the catalyst was first irradiated under UV light for $30 \mathrm{~min}$ to remove any residual organic contaminants. The catalyst $(5 \mathrm{mg})$ was dispersed in an aqueous $\mathrm{RhB}$ solution $\left(25 \mathrm{~mL}, 2 \times 10^{-5}\right.$ $\mathrm{mol} \mathrm{L}^{-1}$ ) in a $50 \mathrm{~mL}$ reactor cell and the solution was stirred in dark condition for $30 \mathrm{~min}$ to ensure adsorption of the dye. A $300 \mathrm{~W} \mathrm{Hg}$ lamp with a $365 \mathrm{~nm}$ filter was used as the source of excitation (Xujiang XPA-7). The concentration of RhB was measured using a UV-vis spectrophotometer (HR2000CG-UV-NIR, Ocean Optics). The concentration of $\mathrm{RhB}$ in the reaction media was followed as a function of time by using the intensity of the $553 \mathrm{~nm}$ absorption peak in order to obtain the kinetic data.

\section{RESULTS AND DISCUSSION}

It has been widely proposed that the multiple reflections of light within $\mathrm{TiO}_{2}$ hollow spheres can improve light harvesting and therefore enhance the photocatalytic activity, as shown in Fig. 1a. In photocatalysis, the activity of a catalyst is usually evaluated based on the same mass of the semiconducting materials. Therefore, to investigate the effect of multiple reflections, we need to compare the light absorption of $\mathrm{a} \mathrm{TiO}_{2}$ sphere and a hollow shell with the same mass. Absorption cross section is a measurement for the probability of an absorption process. More generally, cross section is used to quantify the probability of a certain light-particle interaction. Thus, we firstly calculated the cross sections of extinction, scattering, and absorption of solid and hollow $\mathrm{TiO}_{2}$ spheres based on Mie scattering theory by assuming a fixed mass. As shown in Fig. 1b, the $\mathrm{TiO}_{2}$ hollow shells evolve from a solid sphere by increasing the internal radius but maintaining the shell volume equal to the solid sphere. Firstly, $\mathrm{TiO}_{2}$ hollow shells with the diameters ranged within 0-600 nm was calculated, as shown in Figs 1c-e. The scale bar from blue to red represents the

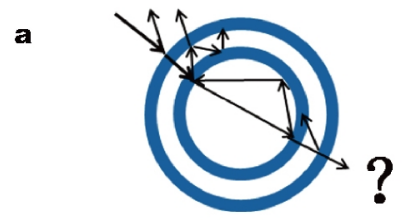

b
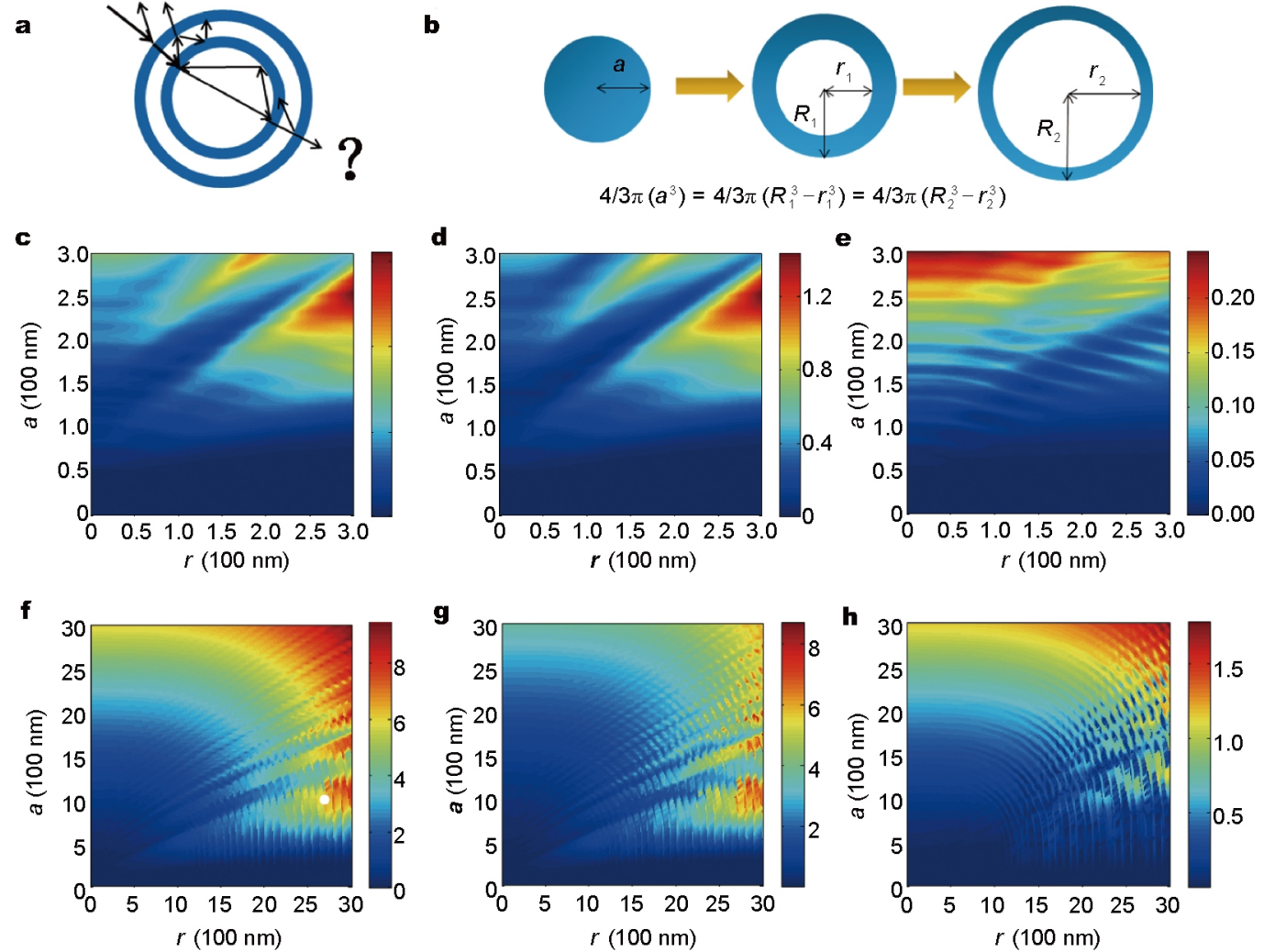

Figure 1 (a) The schematic of multiple reflections within the hollow structure (adapted from Ref. [23]). (b) The schematic evolution of a TiO ${ }_{2}$ hollow shell from a solid sphere by gradually increasing the internal radius but maintaining the volume. Theoretical (c, f) extinction, (d, g) scattering and (e, h) absorption cross sections of the $\mathrm{TiO}_{2}$ hollow shells to $365 \mathrm{~nm}$ UV light. 
relative light intensity of the cross sections. In the simulations presented, the vertical axis indicates the radius of the solid $\mathrm{TiO}_{2}$ spheres, while the horizontal axis indicates the internal radius of $\mathrm{TiO}_{2}$ hollow shells. From this, it is observed that the extinction and the scattering intensity are very low in the Rayleigh region [33]; whereas in the Mie region, both the extinction and the scattering increase with the increasing of the solid particle size and the internal radius of hollow shells, showing a fluctuating distribution along the vertical and the horizontal axis. As a result, both the extinction and the scattering of hollow shell are much stronger than that of the corresponding solid sphere. The absorption also increases with the size of the $\mathrm{TiO}_{2}$ spheres. Based on the same mass of $\mathrm{TiO}_{2}$, with an increase of the radius of the inner cavity along the $x$-axis, the hollow shells become thinner and bigger. It is observed that the extinction of hollow shells is much stronger than the corresponding solid sphere (Fig. 1c). However, it can be found that the scattering of the hollow shell is also stronger than the solid one. By comparing the extinction and scattering, we are able to confirm that the higher extinction intensity of hollow shells is due to the scattering, rather than the absorption. The absorption of the hollow shell actually shows a similar intensity with the solid sphere (Fig. 1e), suggesting that there might be no multiple reflections within the hollow shell which can enhance the light harvesting efficiency. According to the theory of geometrical optics, the multiple reflections within the interior cavity of the hollow shell may occur when the particle size is much larger than the wavelength of the incident light $[33,34]$. Hence, we further expand the diameter of the $\mathrm{TiO}_{2}$ shells up to 6 $\mu \mathrm{m}$ for calculation, with the simulated results shown in Figs 1f-h. The extinction and absorption of $\mathrm{TiO}_{2}$ increase with the radius of solid spheres ( $y$ axis) and the internal radius of the hollow shells ( $x$ axis). By comparing the intensity of extinction, scattering, and absorption, it is found that for the larger $\mathrm{TiO}_{2}$ particles, the extinction of light is mainly due to the absorption and the scattering is relatively low. The $\mathrm{TiO}_{2}$ hollow shells show a notably stronger absorption than the solid sphere when the radius is beyond $1.5 \mu \mathrm{m}$ (Fig. $1 \mathrm{~h}$ ), which can be explained by the possible multiple reflections within the cavity of the hollow structure. It seems reasonable then to conclude that for the submicron $\mathrm{TiO}_{2}$ hollow shells, no multiple reflections would occur within the shells. Nonetheless, if the diameter of $\mathrm{TiO}_{2}$ hollow shells is much larger (under geometrical optics approximation) than the wavelength of the incident light, there might be multiple reflections within the cavity of $\mathrm{TiO}_{2}$ hollow shells and thus enhance the light harvesting efficiency.
Practically, it is difficult to synthesize a solid $\mathrm{TiO}_{2}$ sphere and $\mathrm{TiO}_{2}$ hollow shell with exactly the same mass and crystallinity to compare their photocatalytic activity. However, the activity enhancement of $\mathrm{TiO}_{2}$ hollow spheres originating from the multiple reflections or the multiple scattering can be tested by comparing the activity before and after breaking the shells. It is assumed that the multiple reflections and the multiple scattering effects that happen on the $\mathrm{TiO}_{2}$ hollow spheres are related to the diameter and shell thickness. Herein, the $\mathrm{TiO}_{2}$ hollow structures with different diameters but similar thickness have been selectively fabricated. A series of hollow $\mathrm{TiO}_{2}$ shells with particle diameters of 180-700 nm spanning over the UV and visible light regime was synthesized by using a $\mathrm{SiO}_{2}$ templating method (see Supplementary information). The external diameters of the $\mathrm{TiO}_{2}$ hollow spheres were controlled to be 190, 300, 450, and $600 \mathrm{~nm}$ (denoted as T190, T300, T450, and T600) by adopting 90, 200, 330, and $490 \mathrm{~nm}$ sized $\mathrm{SiO}_{2}$ spheres as templates, respectively. TEM images of the hollow $\mathrm{TiO}_{2}$ are shown in Figs 2a1-d1. The hollow $\mathrm{TiO}_{2}$ samples show mesoporous structure with monodisperse particle dimensions (Fig. S1). Both the particle size and shell thickness are well controlled, showing a similar shell thickness of 50-60 nm. XRD was employed to further determine the crystalline phase of all $\mathrm{TiO}_{2}$ hollow shells. As shown in Fig. S2, all samples show similar crystallinity with peaks attributable to the anatase crystalline phase of $\mathrm{TiO}_{2}$.

For comparison, the hollow structure was destroyed by grinding of $\mathrm{TiO}_{2}$ samples with an agate mortar, and then the photocatalytic activity of the resultant crushed sample was evaluated. As shown in Fig. S3, the hollow structure was totally destroyed after grinding. Sample T300 was chosen to investigate the change of BET surface area before and after grinding. As shown in Fig. S4, the BET surface area of T300 and the ground sample were 209 and $195 \mathrm{~m}^{2} \mathrm{~g}^{-1}$, respectively, suggesting no major change in the surface area. Afterwards, we tested the UV-driven degradation of RhB by using these samples as catalysts for evaluating the photocatalytic activity. The performance of photocatalysts toward $\mathrm{RhB}$ degradation was measured by monitoring the intensity changes of the $553 \mathrm{~nm}$ peak versus time, as summarized in Figs 2a2-d2. To compare the activity of $\mathrm{TiO}_{2}$ hollow shells before (T) and after grinding $(\mathrm{G})$, the data was also displayed in semilogarithmic form (inset in Figs $2 \mathrm{a} 2-\mathrm{d} 2)$ in order to calculate the first-order reaction rate constants $(k)$. For T190, the crushed sample shows a higher $k$ value $\left(0.039 \mathrm{~min}^{-1}\right)$ than the hollow shells $\left(0.033 \mathrm{~min}^{-1}\right)$. The $k$ value of T300, T450, and T600 are $0.029,0.043$, and $0.026 \mathrm{~min}^{-1}$, respectively, while the crushed samples are 

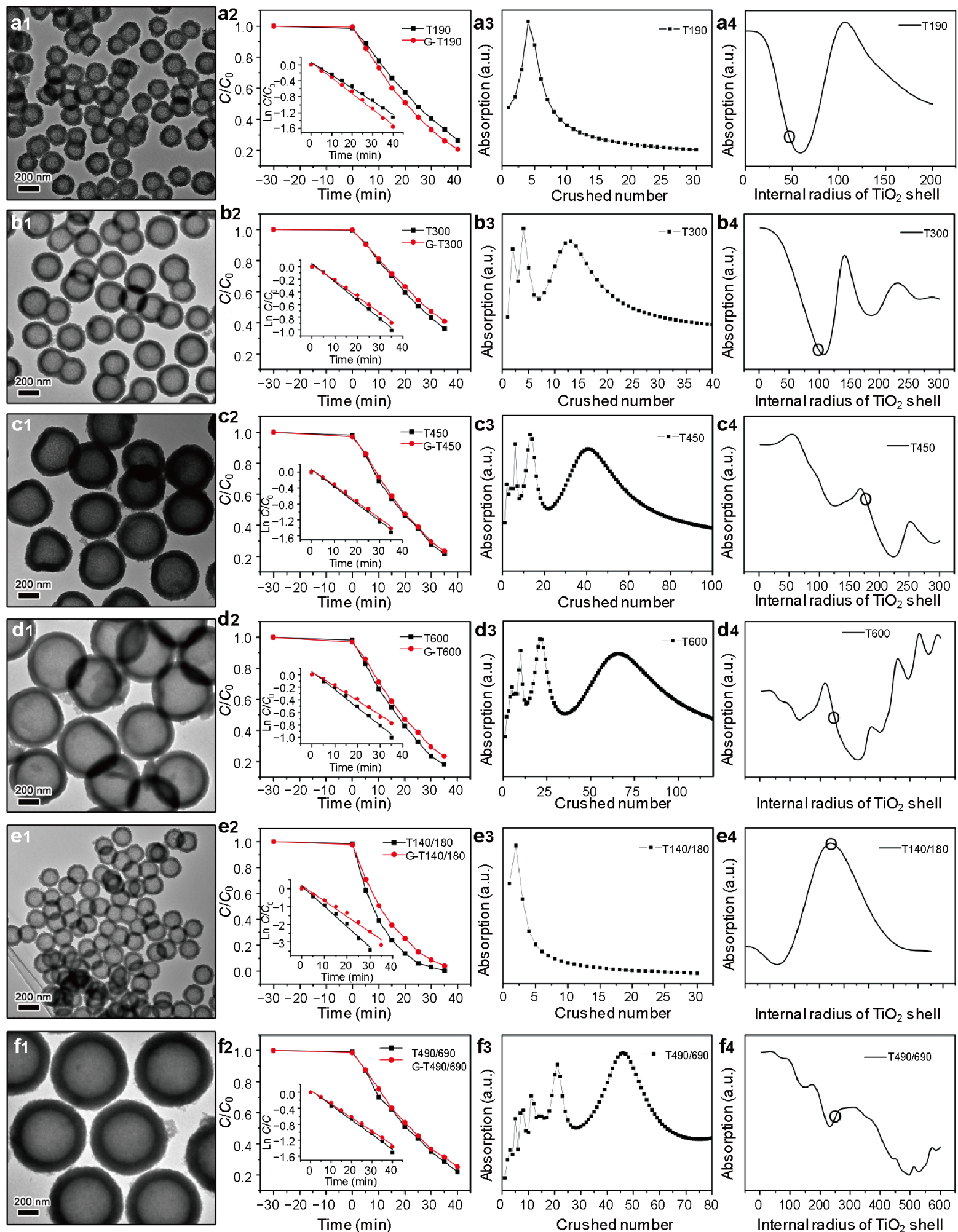

Figure 2 (a1-f1) TEM images of $\mathrm{TiO}_{2}$ hollow shells, (a2-f2) the kinetic plots of the sample for photocatalytic degradation of $\mathrm{RhB}$, and (a3-f3) the absorption cross section of the $\mathrm{TiO}_{2}$ hollow shell over grinding; (a4-f4) the absorption cross section of a solid $\mathrm{TiO}_{2}$ sphere evolved to hollow shells, and the circle indicates the position of the synthesized T190, T300, T450, T600, T140/180, and T490/690. 
$0.026,0.041$, and $0.027 \mathrm{~min}^{-1}$, respectively. It is found that the activity differences of the sample before and after grinding are within $3 \%-10 \%$, suggesting that there is no major light harvesting enhancement in the $\mathrm{TiO}_{2}$ hollow shell.

In addition, we calculated the total absorption cross section of $\mathrm{a} \mathrm{TiO}_{2}$ hollow shell when cracked into several fragments, which is based on Scheme S1 and Equations (S5 and S6) (see Supplementary information). The simulation results show the absorption cross section of UV light (365 $\mathrm{nm}$ ) versus crushing number (Figs $2 \mathrm{a} 3-\mathrm{d} 3$ ), which represents the number of the smaller pieces after crushing. Since it is hard to control how many small pieces are created after grinding, the trend of the absorption cross section versus crushing numbers can help us to understand the trend of activity changes. For the sample T190, as shown in Fig. 2a3, at the beginning of grinding, the absorption increases with the increase of crushed number, suggesting that the absorption can be enhanced by grinding. This can explain why the photocatalytic activity of T190 increases after grinding compared to the hollow shell structure. For T300, T450, and $\mathrm{T} 600$, at the beginning of crushing, the absorption is similar with that of the original $\mathrm{TiO}_{2}$ hollow shell, showing a fluctuating trend. This is probably because of the different size distribution of the crushed samples. For the bigger and thicker hollow shells (T300, T450, and T600), the size distribution of the crushed fragments is broader than that of T190, so the ratio of the crushed fragments which show an appropriate size to cause the Mie resonance is higher, resulting in more absorption peaks, as shown in Figs $2 \mathrm{~b} 3-\mathrm{d} 3$. The overall trend show a similar absorption, in accordance with the similar photocatalytic activity of these samples before and after grinding. Figs $2 \mathrm{a} 4-\mathrm{d} 4$ show the absorption cross section of each hollow shell evolution from a solid sphere with the mass equal to the hollow shell. The circles indicate the position of the synthesized $\mathrm{TiO}_{2}$ hollow shell in this study. It is found that the hollow shell exhibits lower absorption compared to the solid particles. These results indicate that there is no multiple reflections in $\mathrm{TiO}_{2}$ hollow shells from $190-600 \mathrm{~nm}$ with a thickness of about $50-60$ nm.

To further evaluate the light utilization efficiency in $\mathrm{TiO}_{2}$ hollow structures, we synthesized $\mathrm{TiO}_{2}$ hollow shells with different shell thicknesses in order to investigate the light absorption as well as photocatalytic activity. Firstly, the external diameters of the $\mathrm{TiO}_{2}$ hollow spheres were kept similar with T190 but the shell thickness was decreased by adopting $140 \mathrm{~nm}$ sized $\mathrm{SiO}_{2}$ as the template, denoted as T140/180. As shown in Fig. 2e1, the hollow $\mathrm{TiO}_{2}$ samples also show a mesoporous structure with a shell thickness of about $20 \mathrm{~nm}$. The photocatalytic activity of T140/180 before and after grinding was shown in Fig. 2e2. The crushed sample showed a lower activity $\left(k=0.080 \mathrm{~min}^{-1}\right)$ compared to the hollow shells $\left(0.096 \mathrm{~min}^{-1}\right)$. It is interesting that from the calculation result, it can be observed that the absorption cross section is decreasing over the grinding process (Fig. $2 \mathrm{e} 3$ ). The drop in activity may be attributed to the breakage of the hollow shells. According to Mie's scattering theory [34], the incident light will be strongly scattered on the surface of a particle with an appropriate size comparable to its wavelength. When the scattering cross-section exhibits a number of resonances for a given particle size, the scattering will be very efficient at these wavelengths. Here, the size of T140/180 likely matches the incident light $(365 \mathrm{~nm})$ to show Mie resonance, resulting in the enhancement of scattering and absorption of the $\mathrm{TiO}_{2}$ hollow shell, followed by the high light utilization efficiency. It is also confirmed by the simulation of T140/180 from a solid sphere to a hollow shell by gradually increasing the internal radius but maintaining the volume. The calculated absorption was shown in Fig. 2e4. We can easily observe that a hollow shell with a $70 \mathrm{~nm}$ internal radius shows highest absorption intensity, which is consistent with the case of T140/180. After the hollow shells were destroyed, the resonant effect might be decreased or disappear, resulting in lower scattering and absorption and thus lower photocatalytic activity. Afterwards, a bigger and thicker $\mathrm{TiO}_{2}$ hollow shell was prepared by increasing the thickness of T600, denoted as T490/690. As show in Fig. 2f1, the hollow $\mathrm{TiO}_{2}$ samples showed a shell thickness of about $100 \mathrm{~nm}$. Similar photocatalytic activity was observed for T490/690 and the crushed sample (Fig. $2 \mathrm{f} 2$ ). The calculated absorption cross section also shows a fluctuating trend (Figs $2 \mathrm{f} 3$ and f4).

Recent works have also revealed that multi-shelled hollow spheres exhibit a greatly enhanced photocatalytic activity or photoelectric conversion efficiency due to multiple-reflections of light $[37,38]$. To verify the multiple reflections effect in the multi-shelled hollow $\mathrm{TiO}_{2}$, double shelled $\mathrm{TiO}_{2}$ was synthesized by utilizing T450 (Fig. 3a1) as the inner hollow shell, sequential coating with $\mathrm{SiO}_{2}$ and $\mathrm{TiO}_{2}$, and finally dissolving the middle layer of $\mathrm{SiO}_{2}$. Double shelled $\mathrm{TiO}_{2}$ with different inter-shell distance were prepared, noted as D-T550 and D-T670, with their TEM images shown in Figs $3 \mathrm{~b} 1$ and $\mathrm{cl}$. It can be observed that the $\mathrm{TiO}_{2}$ double shells have clear surfaces and a relatively darker core inside. Further investigation of a single sphere by high magnification TEM (inset of Figs $3 \mathrm{~b} 1$ and $\mathrm{c} 1$ ) shows that the inter-shell distances of D-T550 and D-T670 are 10 and $75 \mathrm{~nm}$, respectively. The photocatalytic activities of 

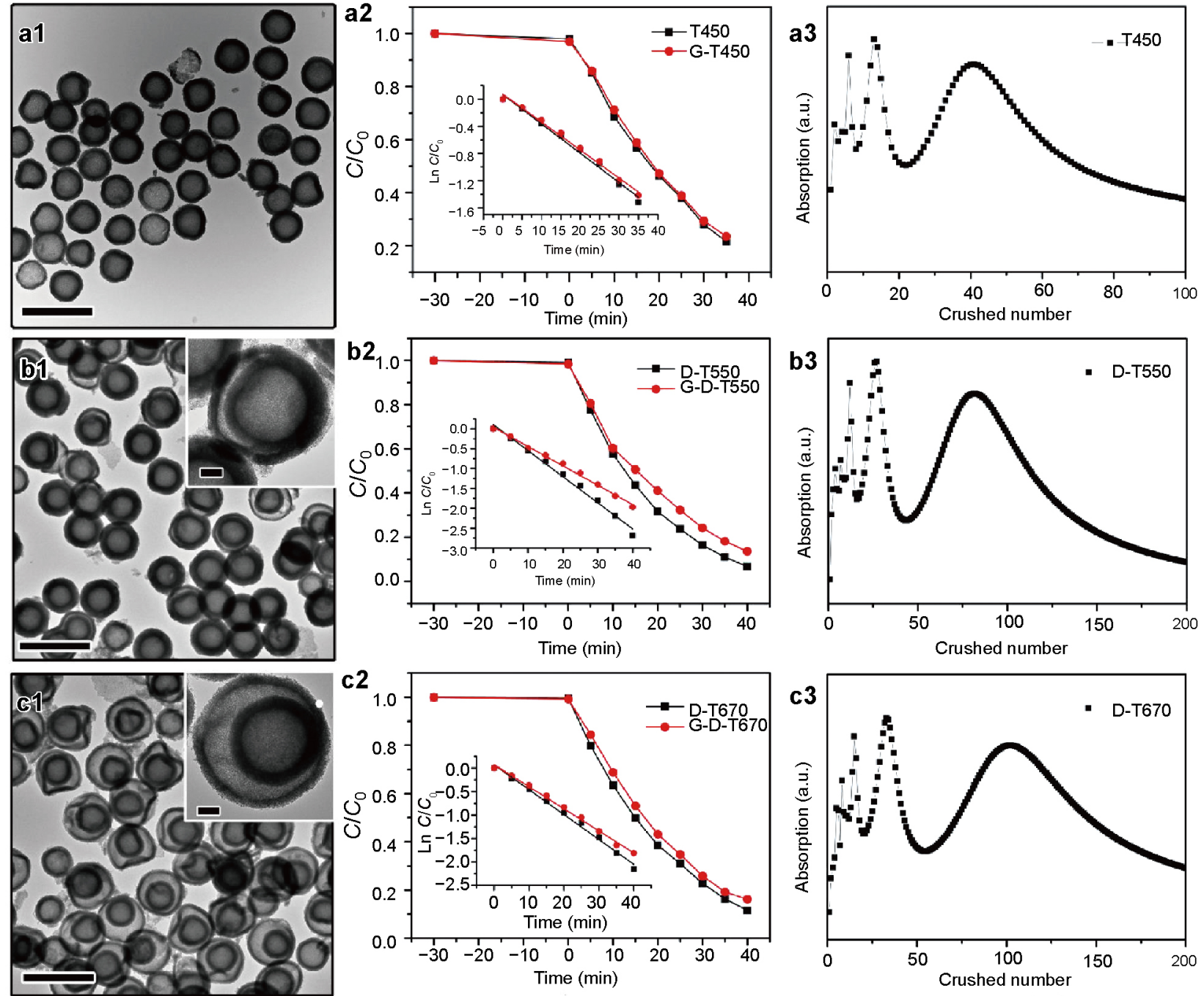

Figure 3 (a1, b1, c1) TEM images, (a2, b2, c2) the kinetic plots of the sample for photocatalytic degradation of RhB, and (a3, b3, c3) the absorption cross section of $\mathrm{TiO}_{2}$ over grinding of T450, D-T550, D-T670. The scale bars in a1, b1, and c1 are $1 \mu \mathrm{m}$ and $100 \mathrm{~nm}$ for the inset, respectively.

D-T550 and D-T-670 before and after grinding were evaluated by the degradation of RhB. The activity of sample D-T550 is shown in Fig. 3b2. It is found that the degradation activity of the double shell and crushed sample are almost the same within the first $10 \mathrm{~min}$, after which the crushed sample shows a lower activity. The $k$ value drops from 0.060 to $0.051 \mathrm{~min}^{-1}$, which is probably due to the diffusion issue. As shown in Fig. 3c2, the crushed sample of D-T670 exhibits a very close degradation activity with the original $\mathrm{TiO}_{2}$ double shell. The first-order reaction rate constants $(k)$ calculated from the kinetic data (inset in Fig. $3 \mathrm{c} 2$ ) are 0.046 and $0.040 \mathrm{~min}^{-1}$ for D-T670 before and after grinding, respectively. There is not much difference in the observed activity, indicating that there are no significant multi-reflections of light within the double shell. The ab- sorption cross section of D-T550 and D-T-670 over grinding was also calculated, as shown in Figs $3 \mathrm{~b} 3$ and c3, where a fluctuating trend was observed for both of the two samples.

Finally, the photocatalytic activities of different $\mathrm{TiO}_{2}$ hollow spheres before and after grinding are summarized in Fig. 4. On the basis of our experimental results, generally only a small difference in the activity was observed for the $\mathrm{TiO}_{2}$ hollow shells before and after grinding. The activity differences are within the error range for most of the samples. A notable difference was for sample T140/180, as $17 \%$ decrease of the activity was observed after grinding. As we discussed previously, this is probably because of the match between the size of the shells (140/180 nm) and the incident light $(365 \mathrm{~nm})$, which leads to resonance and results in the 


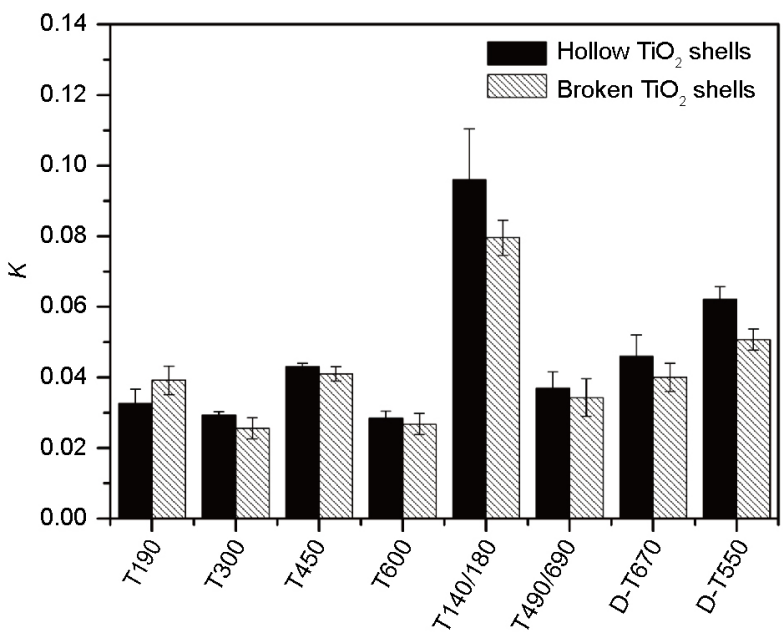

Figure 4 The comparison of the reaction kinetic constant values of different $\mathrm{TiO}_{2}$ hollow shells before and after grinding.

highest light utilization efficiency and activity. However, compared with our previous results about the activity difference caused by the other factors such as crystallinity, phase composition, dispersity [20], the enhancement is more significantly, suggesting that the activity enhancement from the resonance is minor.

\section{CONCLUSIONS}

With theoretical and experimental evidences we reveal that the multiple reflections and multiple scattering of $\mathrm{TiO}_{2}$ hollow structures are size dependent. In the submicron-scale $\mathrm{TiO}_{2}$ hollow shells, there are no significant multiple reflections within the sphere interior voids. The photocatalytic performance of $\mathrm{TiO}_{2}$ hollow structures can be enhanced by the Mie scattering of light only when the size of $\mathrm{TiO}_{2}$ shell matches the wavelength of incident light. However, even when resonance is reached, the activity enhancement by scattering is still very limited. We conclude that for the design of $\mathrm{TiO}_{2}$ photocatalyst with higher activity, it might be more appropriate to focus on the improvement of the crystallinity, diffusion, surface area, and dispersity of the catalyst, rather than its geometric shape. On the other hand, the fabrication processes of hollow shells do offer many other opportunities in structural design for achieving high active surface area, reduced diffusion resistance, and improved accessibility, which are highly desired features in photocatalysis.

Received 8 September 2016; accepted 22 September 2016; published online 14 November 2016

1 Caruso F, Caruso RA, Moehwald H. Nanoengineering of inorganic and hybrid hollow spheres by colloidal templating. Science, 1998 ,
282: 1111-1114

2 Arnal PM, Comotti M, Schüth F. High-temperature-stable catalysts by hollow sphere encapsulation. Angew Chem, 2006, 118: 8404-8407

3 He Q, Wu Z, Huang C. Hollow magnetic nanoparticles: synthesis and applications in biomedicine. J Nanosci Nanotech, 2012, 12: 2943-2954

4 Nai J, Tian Y, Guan X, et al. Pearson's principle inspired generalized strategy for the fabrication of metal hydroxide and oxide nanocages. J Am Chem Soc, 2013, 135: 16082-16091

5 Sun Y, Wiley B, Li ZY, et al. Synthesis and optical properties of nanorattles and multiple-walled nanoshells/nanotubes made of metal alloys. J Am Chem Soc, 2004, 126: 9399-9406

6 Fan C, Bian T, Shang L, et al. pH-Responsive reversible self-assembly of gold nanoparticles into nanovesicles. Nanoscale, 2016, 8: 3923-3925

7 Bian T, Shang L, Yu H, et al. Spontaneous organization of inorganic nanoparticles into nanovesicles triggered by UV light. Adv Mater, 2014, 26: 5613-5618

8 Koo HJ, Kim YJ, Lee YH, et al. Nano-embossed hollow spherical $\mathrm{TiO}_{2}$ as bifunctional material for high-efficiency dye-sensitized solar cells. Adv Mater, 2008, 20: 195-199

9 Zhou C, Zhao Y, Bian T, et al. Bubble template synthesis of $\mathrm{Sn}_{2} \mathrm{Nb}_{2} \mathrm{O}_{7}$ hollow spheres for enhanced visible-light-driven photocatalytic hydrogen production. Chem Commun, 2013, 49: 9872-9874

10 Liang HP, Zhang HM, Hu JS, et al. Pt hollow nanospheres: facile synthesis and enhanced electrocatalysts. Angew Chem Int Ed, 2004, 43: 1540-1543

11 Lou XW, Wang Y, Yuan C, et al. Template-free synthesis of $\mathrm{SnO}_{2}$ hollow nanostructures with high lithium storage capacity. Adv Mater, 2006, 18: 2325-2329

12 Cao CY, Guo W, Cui ZM, et al. Microwave-assisted gas/liquid interfacial synthesis of flowerlike $\mathrm{NiO}$ hollow nanosphere precursors and their application as supercapacitor electrodes. J Mater Chem, 2011, 21: 3204-3209

13 Lai X, Halpert JE, Wang D. Recent advances in micro-/nano-structured hollow spheres for energy applications: from simple to complex systems. Energy Environ Sci, 2012, 5: 5604-5618

14 Zhao Y, Jia X, Waterhouse GIN, et al. Layered double hydroxide nanostructured photocatalysts for renewable energy production. Adv Energy Mater, 2016, 6: 1501974

15 Kudo A, Miseki Y. Heterogeneous photocatalyst materials for water splitting. Chem Soc Rev, 2009, 38: 253-278

16 Macwan DP, Dave PN, Chaturvedi S. A review on nano- $\mathrm{TiO}_{2}$ sol-gel type syntheses and its applications. J Mater Sci, 2011, 46: 3669-3686

17 Joo JB, Zhang Q, Lee I, et al. Mesoporous anatase titania hollow nanostructures though silica-protected calcination. Adv Funct Mater, 2012, 22: 166-174

18 Joo JB, Zhang Q, Dahl M, et al. Control of the nanoscale crystallinity in mesoporous $\mathrm{TiO}_{2}$ shells for enhanced photocatalytic activity. Energy Environ Sci, 2012, 5: 6321-6327

19 Joo JB, Lee I, Dahl M, et al. Controllable synthesis of mesoporous $\mathrm{TiO}_{2}$ hollow shells: toward an efficient photocatalyst. Adv Funct Mater, 2013, 23: 4246-4254

20 Liu H, Joo JB, Dahl M, et al. Crystallinity control of $\mathrm{TiO}_{2}$ hollow shells through resin-protected calcination for enhanced photocatalytic activity. Energy Environ Sci, 2015, 8: 286-296

21 Li H, Bian Z, Zhu J, et al. Mesoporous titania spheres with tunable chamber stucture and enhanced photocatalytic activity. J Am Chem Soc, 2007, 129: 8406-8407 
22 Shi JW, Zong X, Wu X, et al. Carbon-doped titania hollow spheres with tunable hierarchical macroporous channels and enhanced visible light-induced photocatalytic activity. ChemCatChem, 2012, 4: 488-491

23 Wu X, Lu GQM, Wang L. Shell-in-shell $\mathrm{TiO}_{2}$ hollow spheres synthesized by one-pot hydrothermal method for dye-sensitized solar cell application. Energy Environ Sci, 2011, 4: 3565-3572

24 Zhao T, Liu Z, Nakata K, et al. Multichannel $\mathrm{TiO}_{2}$ hollow fibers with enhanced photocatalytic activity. J Mater Chem, 2010, 20: 5095-5099

25 Kondo Y, Yoshikawa H, Awaga K, et al. Preparation, photocatalytic activities, and dye-sensitized solar-cell performance of submicronscale $\mathrm{TiO}_{2}$ hollow spheres. Langmuir, 2008, 24: 547-550

$26 \mathrm{Yu} \mathrm{J}, \mathrm{Yu} \mathrm{X}$. Hydrothermal synthesis and photocatalytic activity of zinc oxide hollow spheres. Environ Sci Technol, 2008, 42: 4902-4907

27 Wang X, Liao M, Zhong Y, et al. ZnO hollow spheres with doubleyolk egg structure for high-performance photocatalysts and photodetectors. Adv Mater, 2012, 24: 3421-3425

28 Song X, Gao L. Facile synthesis and hierarchical assembly of hollow nickel oxide architectures bearing enhanced photocatalytic properties. J Phys Chem C, 2008, 112: 15299-15305

29 Zhu Y, Wang L, Huang G, et al. Luminescent and photocatalytic properties of hollow $\mathrm{SnO}_{2}$ nanospheres. Mater Sci Eng-B, 2013, 178: 725-729

30 Luo M, Liu Y, Hu J, et al. One-pot synthesis of CdS and Ni-doped CdS hollow spheres with enhanced photocatalytic activity and durability. ACS Appl Mater Interfaces, 2012, 4: 1813-1821

31 Yu J, Yu X, Huang B, et al. Hydrothermal synthesis and visiblelight photocatalytic activity of novel cage-like ferric oxide hollow spheres. Cryst Growth Des, 2009, 9: 1474-1480

32 Sun J, Zhang J, Zhang M, et al. Bioinspired hollow semiconductor nanospheres as photosynthetic nanoparticles. Nat Commun, 2012, 3: 1139
33 Born M, Wolf E. Principles of Optics (7th Edition). Cambridge: Cambridge University Press, 1999

34 Bohren CF, Huffman DR. Absorption and Scattering of Light by Small Particles. Weinheim: Wiley-VCH, 2004

35 Stöber W, Fink A, Bohn E. Controlled growth of monodisperse silica spheres in the micron size range. J Colloid Interface Sci, 1968, 26: $62-69$

36 Zhang Q, Zhang T, Ge J, et al. Permeable silica shell through surface-protected etching. Nano Lett, 2008, 8: 2867-2871

37 Zeng $\mathrm{Y}$, Wang $\mathrm{X}$, Wang $\mathrm{H}$, et al. Multi-shelled titania hollow spheres fabricated by a hard template strategy: enhanced photocatalytic activity. Chem Commun, 2010, 46: 4312-4314

38 Qian J, Liu P, Xiao Y, et al. $\mathrm{TiO}_{2}$-coated multilayered $\mathrm{SnO}_{2}$ hollow microspheres for dye-sensitized solar cells. Adv Mater, 2009, 21: 3663-3667

Acknowledgments Yin Y is grateful for the support from the U.S. Department of Energy, Office of Science, Basic Energy Sciences, Chemical Sciences, Geosciences, \& Biosciences (CSGB) Division (DE-SC0002247). Liu $\mathrm{H}$ acknowledges the support from the National Natural Science Foundation of China (21501081, 21571089, and 21401091) and the Fundamental Research Funds for the Central Universities (SWU116010 and lzujbky-2015-19).

Author contributions Yin $\mathrm{Y}$ and Liu $\mathrm{H}$ designed the project. Liu $\mathrm{H}$ performed the experiments and wrote the paper with support from Yin Y and Joo J. Ma H contributed to the theoretical calculations and analysis. All authors contributed to the general discussion.

Conflict of interest The authors declare that they have no conflict of interest.

Supplementary information Simulations and calculations, high magnification TEM images, XRD patterns, and surface area of the selected $\mathrm{TiO}_{2}$ hollow shells are available in the online version of the paper. 


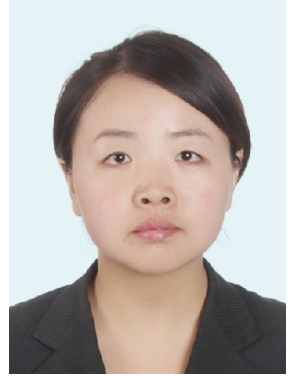

Hongyan Liu is an associate professor at the College of Chemistry and Chemical Engineering, Southwest University. Her research is focused on the synthesis of nanostructures and their applications in photocatalysis and photoelectrochemical biosensors.

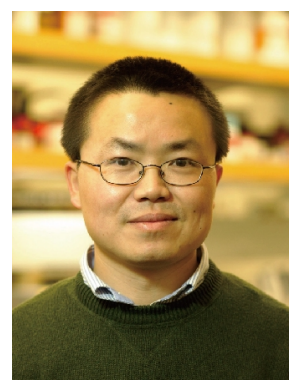

Yadong Yin is a professor at the Department of Chemistry, University of California, Riverside. His research is focused on the synthesis and application of nanostructured materials, self-assembly processes, and colloidal and interface chemistry.

\section{纳米二氧化钛空心球中的多重反射对于光的吸收效率的影响}

刘红艳 $1,2,3^{*}$, 马华 ${ }^{2}$, Jibong Joo ${ }^{2,4}$, 殷亚东 ${ }^{2 *}$

摘要 本文通过理论模拟和实验相结合的方法, 研究了 $\mathrm{TiO}_{2}$ 纳米空心球内的多重反射和多重散射作用及其对光催化活性的影响. 首先通过 基于米氏散射理论的模拟, 计算了 $\mathrm{TiO}_{2}$ 空心球的消光、吸收和散射. 进而合成了不同尺寸和不同结构的 $\mathrm{TiO}_{2}$, 通过对比空心球研磨前后光 催化的活性来验证空心球内多重反射是否存在及其对光催化活性的影响. 研究指出, $\mathrm{TiO}_{2}$ 纳米空心球内部并没有多重反射. 空心球之间的 多重散射对催化活性的贡献也很小. 因此, 设计高活性的光催化剂, 应该集中在对催化剂晶粒尺寸和晶相的控制, 以及引入复合催化剂提高 电子空穴的利用效率, 而不是材料的几何结构本身. 